\title{
Contributos da abordagem dos saberes populares para o ensino de Química
}

\author{
Contributions of the approach of popular knowledge to the teaching of \\ Chemistry
}

\section{Contribuciones del enfoque del conocimiento popular a la enseñanza de la Química}

\author{
Laís Frantz de Faria (lais-ff@hotmail.com) \\ Universidade Federal de Santa Maria-UFSM. \\ Eril Medeiros da Fonseca (erilmf@gmail.com) \\ Universidade Federal do Pampa-UNIPAMPA.
}

Renata Hernandez Lindemann (renatalindemann@unipampa.edu.br)

Universidade Federal do Pampa-UNIPAMPA.

Resumo:Este trabalho discute uma proposta implementada em aulas de Química acerca dos saberes populares da produção de pão e vinho. A intervenção pedagógica foi desenvolvida com alunos do terceiro ano do ensino médio de uma escola estadual de Dom Pedrito, RS. Realizaram-se distintas atividades que permitiram a participação ativa dos estudantes. A utilização dos saberes populares articulados ao ensino de Química permitiu identificar indícios de apropriação da linguagem química, perceber a potencialidade do trabalho coletivo e ressignificar a prática pedagógica.

Palavras-chave: Ensino de química; Saberes populares; Fermentação.

\begin{abstract}
This work discusses a proposal implemented in Chemistry classes about the popular knowledge of bread and wine production. The pedagogical intervention was developed with students from the third year of high school at a state school in Dom Pedrito, RS. Different activities were carried out that allowed the active participation of students. The use of popular knowledge linked to the teaching of Chemistry allowed to identify signs of appropriation of the chemical language, to perceive the potential of collective work and to re-signify the pedagogical practice.
\end{abstract}

Keywords: Chemistry teaching; Popular knowledge; Fermentation.

Resumen: Este artículo analiza una propuesta implementada sobre el conocimiento popular de la producción de pan y vino, en las clases de Química. La intervención pedagógica se desarrolló con alumnos de $3^{\circ}$ de bachillerato de un colegio público de Dom Pedrito-RS. Se realizaron diferentes producciones textuales, que permitieron la participación activa de los estudiantes. Se señala que el conocimiento popular articulado 
a la enseñanza de la química, permitió identificar signos de apropiación del lenguaje químico, percibir el potencial del trabajo colectivo y resignificar la práctica pedagógica.

Palabras-clave: Enseñanza de Química; Conocimientos populares; Fermentación.

\section{INTRODUÇÃO}

O mundo atual exige que o estudante tome decisões. Essas decisões são construídas nas interações sociais vivenciadas na escola através de uma visão orgânica do conhecimento, de interações entre as disciplinas e da relação entre os conteúdos do ensino com os contextos de vida social e pessoal. A contextualização escolar pode ocorrer por meio de situações reais, discutindo questões ambientais, sociais, políticas, culturais e éticas, o que propicia maior responsabilidade e capacidade de tomada de decisão, desenvolvendo atitudes e valores comprometidos com a cidadania, na busca pela preservação ambiental e pela igualdade econômica, social e cultural. A Base Nacional Comum Curricular (BNCC) para o Ensino Médio (BRASIL, 2017) tem reforçado essa importância.

No geral, os estudantes mostram-se mais interessados pelo processo de aprendizagem quando o conteúdo é relacionado com sua realidade, por isso, abordagens contextualizadas contribuem para essa perspectiva. O contexto das discussões deste trabalho é o município de Dom Pedrito, RS, que se localiza em uma região essencialmente agropastoril por tradição, tendo sua economia baseada na criação de gado e na produção agrícola de arroz e soja. Vem se destacando na produção de uvas viníferas de excelente qualidade, que são matéria-prima para grandes vinícolas, bem como para produtores artesanais de vinho.

A produção artesanal de vinho e pães caseiros é uma atividade realizada por alguns moradores da localidade e foi escolhida como tema deste trabalho. Assim, elaborou-se uma intervenção de ensino envolvendo a temática de produção de pão e vinho, tendo em vista a abordagem dos saberes populares em sala de aula. Autores como Chassot (2008), Ferreira et al. (2019) e Santos e Moura (2020) argumentam sobre a relevância do trabalho com saberes populares articulados aos saberes escolares para potencializar a aprendizagem, considerando outra forma de ver o mundo. Essa 
perspectiva tem como propósito ser uma estratégia didática diferenciada, inovadora e capaz de inserir o cotidiano do aluno na escola como uma possibilidade de experimentálo e compreendê-lo de forma diferente.

Considerando o processo de produção de pão e vinho e a relevância de um ensino vinculado a aspectos locais, neste trabalho, discute-se uma intervenção de ensino em aulas de Química sobre os saberes populares da produção de pão e vinho. É importante incluir que este estudo é produto atualizado de um processo de pesquisa no âmbito do Mestrado Profissional em Ensino de Ciências da Unipampa, Campus Bagé.

\section{SABERES POPULARES PARA APRENDIZAGEM EM QUÍMICA}

A abordagem contextualizada sobre aspectos locais em processos de ensino tem sido uma tendência na educação (CHASSOT, 2008; RESENDE; CASTRO; PINHEIRO, 2010) a partir da perspectiva construtivista na elaboração dos currículos, sendo importante valorizar a cultura, os recursos e os problemas locais, assim como discuti-los.

Para Venquiaruto, Dallago e Del Pino (2014, p. 72), esse movimento de transformar saberes populares em escolares configura-se uma forma de "[...] negociação de significados e de apropriação de conceitos científicos". Ferreira et al. (2019) perceberam que a abordagem dos saberes populares por meio de oficinas temáticas permite novas formas de mediação do conhecimento, sem negligenciar os estudos teóricos da Química em sala de aula, contribuindo para melhorar os conhecimentos escolares e promover aprendizagens. Figaro (2015) abordou as plantas medicinais em sala de aula de Química e no seminário integrado através do resgate de saberes populares e de estratégias diversificadas. Isso contribuiu para a compreensão de conteúdos e da linguagem representacional de estruturas da Química Orgânica.

Os autores anteriormente mencionados debatem que a escola ainda precisa, de alguma forma, valorizar os saberes populares, aspecto que pode contribuir para a contextualização do ensino. Parece ser importante a escola reconhecer os saberes populares dos mais velhos como fonte de conhecimento a ser compreendido, pois tais saberes podem ser levados à sala de aula. Desse modo, é relevante a identificação dos saberes populares locais como forma de garantir sua compreensão e problematização 
em práticas escolares que garantam a abordagem do contexto. Lima e Robaina (2020) mencionam que a articulação entre os saberes populares e os científicos possibilita integrar diferentes conhecimentos, de modo que possa capacitar os sujeitos a transformar e potencializar sua realidade local.

Gondim e Mól (2008) apresentaram uma proposta de ensino de Ciências no sentido de orientar professores de Química em práticas pedagógicas que relacionem saberes populares e científicos. Os autores utilizaram a abordagem temática para desenvolver uma proposta de ensino na forma de um material paradidático acerca da tecelagem mineira, apostando na interdisciplinaridade e contextualização.

Para Chassot (2004), a transmissão dos conhecimentos químicos necessita estar encharcada na realidade, de forma a ensinar química que destaque o seu papel social, contextualizando-a de forma histórica, social, política e econômica. $\mathrm{O}$ autor defende que os conteúdos podem ser pensados a partir da realidade dos alunos. Chassot (2007) ainda acrescenta que o ensino de química não deve ocorrer apenas pela aplicação de fórmulas, estruturas, decorando nomenclaturas ou reações. É necessário que se desenvolva, no aluno, a capacidade de observar o que ocorre nas múltiplas situações reais e que se apresentam modificadas a cada instante. Os conhecimentos adquiridos com a família e com a comunidade podem ser usados em sala de aula, relacionando os saberes populares e os saberes escolares.

\section{A PROPOSTA DE ENSINO}

O trabalho foi desenvolvido com 36 alunos de terceira série do ensino médio de uma escola estadual, no componente curricular de Química, e contou com o planejamento e desenvolvimento de 14 aulas para levantamento e estudo da realidade. Os estudantes foram inseridos em um contexto de pesquisa, entrevistando familiares e pessoas de suas relações, que, atualmente ou em outras épocas, tenham produzido pães (a partir de fermentos caseiros ou com fermento biológico) e vinhos, a fim de compreender como eles são obtidos, resgatando essa cultura popular e trazendo, para a aula, temáticas a serem estudadas. A sequência de ensino (Quadro 1) considerou atividades que proporcionassem a interação entre os estudantes, bem como entre eles e a comunidade local. 
Quadro 1 - Planejamento da sequência de ensino

\begin{tabular}{|c|l|}
\hline Aula & \multicolumn{1}{|c|}{ Conteúdo/Recursos e Metodologias } \\
\hline 1 & Aplicação de questionário. \\
\hline 2 & Organização experimento da uva. Texto 1 (Crônicas: Fermentação). \\
\hline 3 & Observação experimento da uva. Organização da turma para trabalho em grupo.* \\
\hline 4 & Observação fermentação da uva e confecção do relato escrito. \\
\hline 5,6 & $\begin{array}{l}\text { Observação fermentação da uva com escrita de relato. Leitura e discussão do texto } \\
\text { 2 (Fermentação). Discussão das reações de fermentação e da história do pão, cerveja } \\
\text { e vinho. Apresentação Grupo 1. }\end{array}$ \\
\hline 7,8 & $\begin{array}{l}\text { Observação da fermentação da uva com registro escrito. Releitura texto 2. } \\
\text { Apresentação Grupos 2, 3 e 4. Escrita sobre: como explicar, usando termos da } \\
\text { ciência, o processo fermentativo do pão? }\end{array}$ \\
\hline 9 & $\begin{array}{l}\text { Apresentação Grupos 5 e 6. Observação fermentação da uva. Escrita sobre: como } \\
\text { explicar, usando termos da ciência, o processo de transformação da uva em vinho? }\end{array}$ \\
\hline 10,11, & $\begin{array}{l}\text { Temperatura e densidade, problematizando saberes populares do pão. Produção de } \\
\text { pão de fermento de batatinha e de fermento biológico. Realização dos } \\
\text { experimentos: densidade e temperatura. }\end{array}$ \\
\hline 13 & $\begin{array}{l}\text { Leitura e discussão do texto 3 (Química do Pão). Retomada cinética química. } \\
\text { Questionário final. }\end{array}$ \\
\hline 14 & \begin{tabular}{l} 
Alunos responderam a questões discursivas e a testes de vestibular e ENEM. \\
\hline
\end{tabular}
\end{tabular}

* Organizado para a pesquisa dos alunos através de entrevistas com pessoas da comunidade e com familiares e de pesquisa em bancos de dados relacionados à produção do pão, do vinho e da cerveja. Fonte: Simplificado de Faria (2015, p. 47)

A seguir, discute-se a implementação da sequência que se compreende como contribuições sobre os saberes populares na aprendizagem em Química. Isso se reforça a partir da análise de três aspectos emergentes. Para tanto, analisaram-se as gravações das aulas e as produções dos alunos e da pesquisadora. Adotou-se o uso de nomes fictícios para resguardar a identidade dos sujeitos e discutiu-se individualmente a fala de cada aluno, com o intuito de perceber alterações.

\section{INDÍCIOS DE APROPRIAÇÃO DA LINGUAGEM QUÍMICA}

Sobre a estudante Betina, é importante registrar que ela foi pouco frequente às aulas. Participou de 8 das 14 aulas e, sempre que solicitada sua participação, apresentava um comportamento indiferente. Ao ser questionada na primeira aula sobre como é feito o pão, sobre como é o processo de crescimento de um bolo e como se explica o processo de fabricação de bebidas como a cerveja e o vinho, disse: "Ele é feito com farinha, leite, ovo, fermento etc. Através da fermentação. Não sei." (Betina). Observa-se que a estudante descreveu os ingredientes e não os procedimentos de produção. 
Além disso, embora respondendo de forma adequada à questão, ela pode não ter percebido relação no processo químico ocorrido com a produção de bolos e pães e a produção de bebidas fermentadas. Em outro momento, ao explicar o processo fermentativo do pão, usando termos da ciência, Betina destacou que: "Ele pode acontecer com a ajuda de elementos naturais ou industrializados e sua função é encorpar a massa; a fermentação ocorre quando se mistura a farinha e a água na produção na massa. $\mathrm{O}$ amido e o oxigênio juntos se transformam em açúcar. $\mathrm{O} \mathrm{CO}_{2}$ é o principal elemento e tem grande importância na fermentação do pão”. (Betina). Observa-se que a aluna incorporou, em sua explicação, termos como elementos, fermentação, amido, oxigênio, transformação e $\mathrm{CO}_{2}$.

É possível perceber que a estudante busca explicitar e inserir, em sua explicação, termos discutidos em aula. Parece considerar o $\mathrm{CO}_{2}$ como uma substância ao invés de uma molécula. Acredita-se que essa atribuição se deva ao fato de ela ainda não ter distinguido os conceitos utilizados ( $\mathrm{CO}_{2}$, molécula e substância). Betina explicou que é uma reação de fermentação e ocorria pela presença de dois ingredientes do preparo do pão, porém, desconsiderou o fermento na explicação. Embora tenha utilizado termos químicos, ela apresenta lacunas conceituais que podem ser atribuídas como um obstáculo à aprendizagem, que precisam ser consideradas nos processos de ensino.

Ao final da proposta, a estudante estabeleceu relação entre a produção caseira de pães e a fermentação: "Na formação do pão e do vinho, são usados vários elementos químicos, gás carbônico, oxigênio. O gás carbônico auxilia no crescimento do pão, e o oxigênio, o vinho, que, quando o oxigênio entra em contato com a uva, ao invés de vinho, obtém-se vinagre”. (Betina). Observa-se que ela reconhece que tanto o gás carbônico como o oxigênio contribuem no processo fermentativo do pão e do vinho. Por outro lado, a estudante pareceu ainda não distinguir elemento químico e substância, termos abordados na primeira série do ensino médio, apropriando-se parcialmente dos conteúdos conceituais químicos.

A aluna Mariza mostrou-se entusiasta com as aulas desde o início, assim como vários alunos da turma, sendo participativa. Na primeira aula, ela respondeu que não sabia como era produzido o pão, mas disse que, na sua casa, às vezes, consumia-se pão caseiro feito pela mãe. Refere-se ao processo de crescimento do bolo ou do pão com as 
palavras: "Deixar um bom tempo parado à luz natural". Ao mesmo tempo, atribuiu a produção de cerveja ou vinho à "Fermentação, eu acho".

Durante as aulas, construiu-se e observou-se um processo de fermentação de uvas. Os alunos foram levados ao laboratório para observar e tentar entender o que estava ocorrendo. Mariza destacou: "Está tudo relacionado. Existe química em todo lugar: na nossa comida, no ar que respiramos, nas bebidas que bebemos, incluindo o vinho, que nada mais é que um fenômeno químico”. (Mariza). Percebe-se que Mariza, de forma direta, fez a relação entre o que observava e o processo fermentativo, fenômeno que ocorria. Após serem trabalhados os textos 1 e 2 e após a apresentação dos trabalhos dos grupos sobre pão, Mariza entendeu que o fator temperatura influiu no pão e que ocorreu "captura de $\mathrm{CO}_{2}$ ", bem como a existência de vários tipos de fermento. Nessa aula, Mariza disse: "Este gás carbônico do texto tem a ver com o canudinho?", referindo-se ao experimento com as uvas, cujo suco havia sido colocado numa garrafa com batoque hidráulico improvisado com um canudinho.

Mariza foi extremamente ativa na aula prática de produção de pão e, ao responder o questionário final, referiu: "Se está muito frio, o pão demora muito mais a crescer, por isso a temperatura influencia totalmente no crescimento". (Mariza). Percebe-se que a estudante demonstra ter se familiarizado com termos da ciência e percebe a influência e a importância da temperatura e das leveduras no processo. A respeito da levedura, ela destacou que essa era "responsável pelo aroma e sabor do pão, além de ajudar no processo de fermentação”. (Mariza).

$\mathrm{Na}$ aula, após a produção de pão pelos alunos, apresentou-se a eles o texto 3 . Nessa aula, durante a discussão do tema, surgiram dúvidas relacionadas ao termo "glúten". Alguns alunos prontamente procuraram na internet o que significava, e por sugestão da professora, pesquisaram também sobre problemas de saúde relacionados ao glúten. Mariza não respondeu à questão 10, que era justamente relacionada a essa discussão. Muitas vezes, um excelente aluno também mostra desinteresse por determinados assuntos. Ao mesmo tempo que Mariza pareceu desinteressada, em outro momento do questionário, explicou como compreendia o crescimento do pão: “Ao sovar, formam-se as bolhas de ar e as redes glúten aprisionam as moléculas de $\mathrm{CO}_{2}$, expelidas durante a fermentação. São as bolhas de ar e o glúten que fazem o pão 
crescer". (Mariza). Isso demostrou que ela deve ter se apropriado do conhecimento, usando corretamente os termos. Ao estabelecer uma relação entre a química e a produção caseira de pães e a fermentação, disse: "O pão depende muito da temperatura, dos fermentos para se desenvolver, crescer e ficar de boa qualidade. Sendo assim, os fermentos são um exemplo onde há muita química. Portanto, percebe-se que todos ingredientes dependem um do outro para dar certo. Assim, consegui concluir que isto é simplesmente química”. (Mariza).

Os indícios de apropriação da linguagem química apresentados deram-se de maneira diferenciada entre os estudantes, havendo mudança de comportamento de alguns deles em relação às aulas, pois tornaram-se mais interessados e participativos. Assim, a intervenção de ensino proporcionou a interação social com a comunidade e com os colegas a fim de contribuir para que o discente encontre sentido no que aprende. Compreende-se que o conteúdo a ser aprendido precisa estabelecer alguma relação com a realidade do aluno e, se possível, com experimentação.

\section{O TRABALHO COLETIVO}

Percebeu-se que determinados alunos pouco participativos ou desmotivados mudaram seu comportamento. Um exemplo é o aluno Fabio, que faltava muito às aulas, porém, no momento em que foi solicitado para auxiliar com as filmagens, prontificouse, assumindo não faltar. Ele desenvolveu a tarefa de forma comprometida, tornando-se assíduo e participativo, mencionando que: “[...] aprendemos química com o que está no nosso dia-a-dia, assim sendo mais fácil e melhor nosso aprendizado, as aulas não ficam tanto na teoria”. (Fabio). Além disso, de forma voluntária, após o término da filmagem, também ficou cronometrando o tempo nos experimentos.

Amilton, aluno pouco participativo e que não gostava de estudar, assumiu totalmente a apresentação do seu grupo, fazendo, inclusive, intervenções durante a fala dos demais colegas. Quando foi solicitado que manifestasse o que as aulas e o trabalho em grupo representaram para ele, destacou: "Acho muito importante trabalhos práticos e em grupos. Fermentação é química. Logo que descobrimos os segredos da fermentação, colocamos no papel. Na minha opinião, foi muito bom esse trabalho”. 
(Amilton). Amilton reconheceu a importância do trabalho proposto e a sua satisfação em realizá-lo através de trabalhos práticos e em grupo.

O mesmo aconteceu com o Leo, que é bastante comunicativo, mas que não se envolvia em atividades de grupo. Esse aluno apresentou sozinho o trabalho do grupo, tendo tomado a iniciativa de procurar e marcar a entrevista com o produtor de vinho. $\mathrm{O}$ trabalho desse grupo foi rico em detalhes, sendo que Leo, a todo momento, fazia intervenções. Foi possível perceber que o aluno, ao assumir a liderança em seu grupo, também estimulava os colegas na realização das tarefas. Nas aulas com observação da fermentação da uva, ele chamava os demais para que percebessem os aromas e transformações, e dizia: “[...] um cheiro que 'pra' mim era um aroma de vinho" $e$ “cheiro de álcool confundindo com um vinho”. (Leo).

Durante a produção do pão, Camilo, aluno tímido, pediu para mexer na massa, pois, apesar de sua mãe fazer pão em casa, nunca permitiu a participação dele. Percebese que foi o trabalho coletivo, no qual vários alunos assumiam tarefas e pediam para participar, que estimulou Camilo a participar. Nessa aula, que contou com a participação de toda a turma, muitos alunos expressaram que nunca imaginaram que aprenderiam química na prática.

Em síntese, esse tipo de abordagem envolveu os estudantes, proporcionando seu crescimento individual. Percebeu-se na turma uma grande empolgação pelo trabalho coletivo, especialmente porque alguns alunos mudaram suas atitudes e até mesmo mostraram-se participativos. As atividades em grupo possibilitaram a integração da turma e contribuíram para aprendizagens químicas.

\section{O TRABALHO PEDAGÓGICO}

O estudante Tiago surpreendeu com a sua percepção do trabalho desenvolvido, uma vez que era um aluno que faltava muito às aulas. Ele conseguiu expressar, de forma clara, o seu pensamento: "As aulas de química deixaram de ser uma coisa chata 'pra' se tornarem aulas divertidas, interessantes e diferentes, proporcionando ao professor conhecer mais seus alunos, assim como o aluno conhecer melhor seu professor, não estão sendo apenas aulas de química, mas também um ótimo meio de interação professor-aluno”. (Tiago). O aluno explicitou a questão interação professor-aluno, que não foi referida em nenhuma das aulas, mas que foi algo percebido por ele. Esse é um 
aspecto que chamou a atenção da pesquisadora que implementou a intervenção, proporcionando refletir sobre as aulas, recursos e metodologias empregadas no contexto da sala de aula da educação básica e que pode ser um indicativo de possibilidade de envolver mais os estudantes, bem como de dar novo sentido ao trabalho docente, valorizando os saberes populares que eles podem trazer para a sala de aula.

A aluna Tânia sinalizou os novos conhecimentos dos saberes populares que desconhecia: "Eu diria que aprendi muita coisa, conheci o fermento de batatinha que eu nem sabia que existia [...] aulas muito divertidas, saiu um pouco da rotina”. (Tânia). A estudante expressou seu desconhecimento em relação a outro tipo de fermento e falou da saída da rotina, bem como de aulas que ela considerou divertidas, talvez pelo caráter diferenciado, o que corrobora para o resgate dos saberes populares defendido por Chassot (2008). Outro aspecto presente na fala dos estudantes é em relação às aulas serem divertidas e diferentes, além de as aulas práticas terem despertado um grande interesse da turma pelo trabalho. "Foi muito interessante porque pudemos praticar [...]”. (Mara). “Aulas práticas de química, onde tudo que nós havíamos aprendido teoricamente vimos acontecer na prática, foram as mais interessantes de todas que já tivemos até hoje". (Vera). "Gostei muito de sair da teoria e ver os processos químicos”. (Leo).

Os estudantes destacaram aspectos significativos das aulas, tais como: explorar aspectos práticos, realizar o experimento e poder perceber as transformações. Pareceram expressar que conseguiram, por meio das aulas, perceber a relação existente entre a química e os aspectos do cotidiano, especialmente relacionados a processos fermentativos. Talvez um dos motivos tenha sido o tema proposto, que permitiu práticas acessíveis aos alunos sem o uso de material sofisticado.

A busca por atividades que construíssem conhecimento e proporcionassem a produção de aulas que valorizassem o protagonismo do estudante indicou que é preciso pensar estratégias e investir em sua implementação em sala de aula, bem como buscar formas de mediação para que atividades com essa finalidade possam contribuir de fato para a apropriação de conhecimento e desenvolvimento de habilidades.

A abordagem da pesquisa dos saberes populares articulados aos saberes escolares possibilitou melhor interação professor-aluno, assim como aulas 
contextualizadas e aprendizagens químicas. Além disso, os alunos reconheceram que as aulas se tornaram agradáveis, pois conseguiram perceber sentido ao que aprendiam.

\section{CONSIDERAÇÕES FINAIS}

O trabalho possibilitou a percepção de que questões relacionadas a saberes populares podem estar vinculadas a saberes escolares, porém, é necessário que seja feita a contextualização para viabilizar essa abordagem. Contou-se com o protagonismo dos estudantes para que trouxessem, por meio da pesquisa em grupo, conhecimentos para a sala de aula, tanto provindos da família quanto da comunidade. A abordagem dos saberes populares e a química mostrou-se importante, pois promoveu e estimulou a aprendizagem, dado que os alunos buscaram e trouxeram esses saberes para a aula. Eles passaram a conhecer melhor a sua realidade e a estabelecer relação desses saberes.

Os conceitos foram trabalhados de modo a permitir uma melhor compreensão e contextualização da química. O resgate dos saberes populares e a experimentação no contexto das aulas de química proporcionaram uma nova forma de olhar a sala de aula, em que os alunos deixaram de ser expectadores para se tornarem protagonistas da aprendizagem. Além disso, a inserção dos saberes populares, por meio da pesquisa dos estudantes, também contribuiu para que se apropriassem de conteúdos químicos.

Compreende-se que a percepção da Química como algo do seu cotidiano e a utilização de atividades experimentais nas aulas favoreceram o processo de aprendizagem do aluno através da utilização da temática Fermentação, Pão e Vinho. É necessário incluir a possibilidade de que propostas que envolvam os saberes populares como formas de resgate de práticas culturais esquecidas ou pouco praticadas sejam revisitadas, problematizadas e melhor compreendidas por meio da ciência.

Assim, defende-se que a abordagem pedagógica da química, em uma perspectiva contextualizada, possibilita ao educando aprender criticamente o conhecimento escolar. Seguindo tal pensamento, a escola tem compromisso de respeitar os saberes dos educandos, aproveitando sua experiência, discutindo sua realidade, associando os saberes curriculares e a experiência social que eles trazem, valorizando e resgatando a diversidade cultural, enriquecendo assim o conhecimento, pois, ao mesmo tempo em que se ensina, também se aprende. 


\section{REFERÊENIAS}

BRASIL. Ministério da Educação. Base Nacional Comum Curricular. Brasília, DF: MEC, 2017. Disponível em: http://basenacionalcomum.mec.gov.br/images/BNC C_20dez_site.pdf. Acesso em: 22 mar. 2020.

CHASSOT, A. Educação ComSciência. Santa Cruz do Sul: EDUNISC, 2007.

CHASSOT, A. Saberes populares fazendo-se saberes escolares: uma alternativa para a alfabetização científica. In: V ANPED SUL: pesquisa em educação e compromisso social, 2004. p. 11. Disponível em: http://migre.me/oQ3OS. Acesso em: 09 mar. 2020.

CHASSOT, A. Sete escritos sobre educação e ciência. São Paulo: Cortez, 2008.

FARIA, L. F. Saberes populares locais e reações de fermentação: uma proposta para o Ensino de Química. 2015. Dissertação (de Mestrado em Ensino de Ciências) Programa de Pós-Graduação em Ensino de Ciências - Universidade Federal do Pampa, Bagé, 2015.

FERREIRA, L. C. et al. A obtenção artesanal do Tucupi: Ssaberes Ppopulares e o Eensino de Química. Revista Debates em Ensino de Química, v. 5, n. 1, p. 139-150, 2019.

FIGARO, A. K. O ensino de química e seminário integrado: valorizando a pesquisa do estudante a respeito dos saberes populares das plantas medicinais. 2015. Dissertação (de Mestrado em Ensino de Ciências) - Programa de Pós-Graduação em Ensino de Ciências - Universidade Federal do Pampa, Bagé, 2015.

GONDIM, M. S. C.; MÓL, G. S. Saberes populares e ensino de Ciências: possibilidades para um trabalho Iinterdisciplinar. Química Nova na Escola, n. 30, p. 3-9, 2008.

LIMA, V.; ROBAINA, J. V. Compreensões sobre as licenciaturas em educação do campo em Ciências da Natureza: um olhar para os últimos dez anos de produções científicas. Revista Insignare Scientia - RIS, v. 3, n. 4, p. 303-324, 20 nov. 2020.

RESENDE, D. R.; CASTRO, R. C.; PINHEIRO, P. C. O saber popular nas aulas de Química: relatos de experiência envolvendo a produção de vinho de laranja e a sua interpretação no ensino médio. Química Nova na Escola, 03, 2010. Disponível em: www.qnesc.sbq.org.br/online/qnesc33_4/223-RSA3310.pdf. Acesso em: 09 mar. 2020.

SANTOS, G.; MOURA, A. C. Práticas Pedagógicas Publicadas na Revista Brasileira de Educação do Campo: articulação do Ensino de Ciências e da Educação do Campo.

Revista Insignare Scientia - RIS, v. 3, n. 4, p. 22-40, 20 nov. 2020. 
VENQUIARUTO, L. D.; DALLAGO, R. M.; DEL PINO, J. C. Saberes populares fazendo-se saberes escolares: um estudo envolvendo a produção artesanal do vinho. Revista ENCITEC, v. 4, n. 1, p. 62-73, 2014.

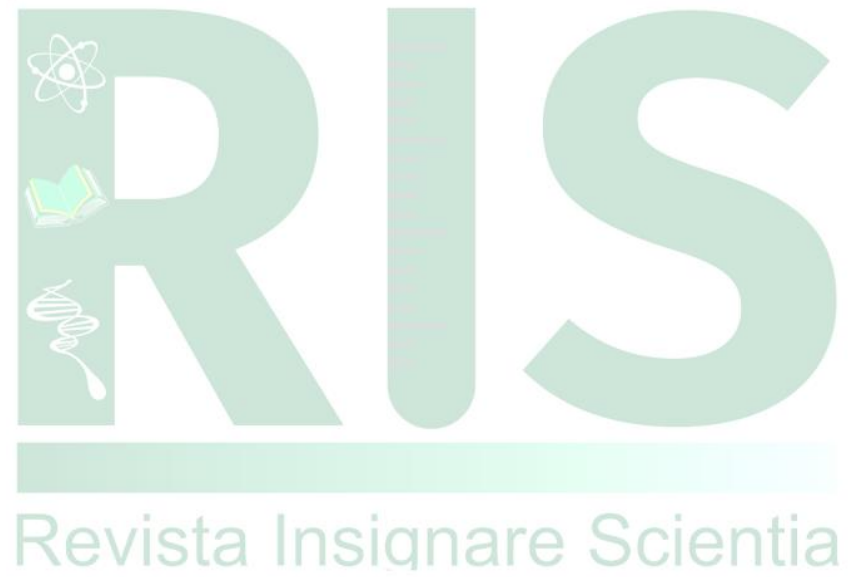

